\title{
MAL Y MUERTE: NOTAS SOBRE LOS APOLOGISTAS
}

\author{
José Cercós Soto \\ Sociedad Internacional Tomás de Aquino. Barcelona
}

Pretendemos examinar cómo se empiezan a entender, en el pensamiento cristiano primitivo, las cuestiones del mal y la muerte. Vamos a iniciar tal examen por los escritos de los apologistas, tanto griegos como latinos, a partir del siglo II de nuestra era.

A todos nos resulta conocido que la finalidad precisa de los escritos de éstos no es la de desarrollar exhaustivamente cuestiones filosóficas, sino la de la defensa del incipiente movimiento cristiano ante los ataques y animadversión tanto de los poderes públicos como de los ciudadanos. Así, S. Justino y Atenágoras, al comienzo de sus obras se dirigen «al emperador». ${ }^{1}$ Mientras que el Discurso contra los griegos, de Taciano, Los tres libros a Autólico, de Teófilo de Antioquía, o el Octavio de Minucio Félix, ${ }^{2}$ como se observa en el mismo título, van destinados a otro tipo de personas, aunque con la misma finalidad.

Por consiguiente, lo que nos interesa sólo es tratado marginalmente -no es lo más urgente $-\mathrm{y}$ dependiendo directamente de la creencia religiosa. Al fin y al cabo esto era lo importante. Porque, se dé en ellos o no una actitud favorable a la filosofía -razón hacia la verdad -, la verdad era vida en ellos; y esa verdad era lo que querían comunicar a través de la palabra. Ante la injusticia, así, la palabra y el ejemplo.

Conscientes, en consecuencia, de la pobreza filosófica de los escritos apologéticos, comenzamos a dar cuenta de lo antes apuntado. Lo que intentaremos hacer sistemáticamente.

\section{LA MUERTE}

Primariamente, el interés por el que nuestros autores llegan a pensar en la muerte no es otro que la preocupación por la inmortalidad. A partir de aquí no pueden dejar de observar

1 Cfr. inicio de Apología I de San Justino, o de la Legación en favor de los cristianos, de Atenágoras, en Ruiz Bueno, Padres apologetas griegos, 2. ㄹ. ed., BAC, Madrid. 1979.

2 Taciano, Discurso contra los griegos, y Teófilo de Alejandría, Los tres libros a Autólico, en Padres apologetas griegos, op. cit. Minucio Félix, Octavio, en P.L., III. 
-a veces es difícil ser consciente de lo evidente— que la muerte es término «natural» en el sentido de lo habitual a lo que el hombre se encuentra sometido- del existir humano sobre esta tierra: «Porque no tememos la muerte, cuando reconocemos que hay absolutamente que morir y nada nuevo sucede en este orden de cosas, sino lo mismo de siempre». ${ }^{3}$ Todo lo nacido ha de perecer. Es el orden comprobable del Universo, la experiencia que cotidianamente se nos impone. En la aceptación de tal orden - aunque han de indagarse las causas- se divide la muerte en «ordinaria» y «extra-ordinaria», aludiendo a la normalidad ono de ella: «ordinariam quidem naturae deputans placidae cujusque mortis; extraordinariam vero praeter naturam judicans violente cuiusque finis». ${ }^{4} \mathrm{O}$ sea, que podemos morir de natural y ordinaria enfermedad, lo cual respeta el normal decurso vital o morir de modo extra-ordinario, violentamente.

¿Qué es la muerte? Como la vida material humana surge en la composición de cuerpo y alma, que más que elementos son «cosas» - según la arraigada tradición platónica一: «homo ex duabus rebus constat, corpore atque animae». ${ }^{5}$ La muerte no puede ser otra cosa que «la separación de cuerpo y alma». ${ }^{6}$ Inmerso en esta tradición, Lactancio no sólo «dualiza» la naturaleza humana sino que contrapone las dos «cosas» de las que se compone como contrarios que se «repugnan» entre sí: cielo y tierra, eterno y temporal, sensible y animal, luz y tinieblas. ${ }^{7}$ La muerte, en consecuencia, ha de pensarse a través de la desaparición del vínculo que une a esas dos realidades de naturaleza diversa. Por lo que la muerte - separación - es provocada por una fuerza capaz de conducir a tal discretio. De cualquier modo el efecto de la separación siempre es el mismo: el progresivo enfriamiento tras la consunción de lo que provoca el calor corporal y la separación de lo que hace vivir. ${ }^{8}$ como cuerpo y alma son de naturaleza distinta, lo que les sucede es diferente. De forma que se puede hablar de una «doble» muerte: la muerte del cuerpo y la del alma.

Porque, por un lado, el cuerpo es de naturaleza terrena, «solidum et comprehensibile [...] et terra fictum atque solidatum est [...] et tangibile est, et visibile [...]; nec vim repellere potest, quia sub aspectum et sub tactum venit». $Y$, por otro, el alma es total y absolutamente distinta: «tenuis, et tactum visumque fugiens [...] in se nihil concreti, nihil terreni ponderis habet», 9 por lo que sólo es explicable su capacidad aludiendo a su origen celestial. La muerte

3 San Justino, Apologia I, n. 57. "Quis enim sapientium dubiat, quis ignorat, omnia quae orta sunt, occidere; quae facta sunt interire?»: Minucio Félix, Octavio, c. 34. «Publica totius generis humani sententia, mortem naturae debitum pronuntiamus»: Tertuliano, Liber de Anima, en P.L., II, c. 50.

4 Tertuliano, op. cit., c. 52.

5 Lactancio, De divinis institutionibus, 1. VII, c. 5, en P.L., VI.

6 Ibid., c. 51; c. 52: «separationem carnis atque animae».

7 «Homo ex rebus diversis ac repugnantibus configuratus est, anima et corpore, id est, coelo atque terra[...] aeterno ac temporali, sensibili atque bruto, luce praedito atque tenebroso»: ibid., c. 4 .

8 «Quos autem morbus interimit, spiritus diutius exhalant, ut paulatim frigescentibus membris anima effletur. Quae cum materia sanguinis contineatur, sicut lumen oleo, ea materia febrium calore comsumpta necesse est membrorum summa quaeque frigescere»: Ibid., c. 12.

9 Id. 
del conjunto, como hemos comentado, exige la separación de las partes. La comprobación de cómo afecta la muerte a cada uno de ellos sólo puede realizarse tras el examen de sus actos y deseos, de lo que es la virtud y el vicio. Lo cual se hará en el siguiente apartado.

¿Qué sucede con la mencionada naturalidad de la muerte? Por una parte, se diría «natural», sólo en cuanto se toma como término de comparación el ser divino: porque «sólo Dios es increado e incorruptible, y por eso es Dios; pero todo lo demás fuera de Dios es creado y corruptible». ${ }^{10}$ Esta «naturalidad» de la muerte no entra dentro de lo que podíamos denominar pura normalidad. Y es así, porque la muerte no forma parte de la esencia del ser humano como tal, sino que es una pasión — padecer- del hombre en la condición en la que se encuentra en este mundo: «aceptamos con amor la vida de necesidades y corrupción como conveniente al tiempo presente». ${ }^{11} \mathrm{O}$ sea, que la mortalidad del hombre no sea esencial puesto que el hombre no fue constituido originalmente en la muerte ${ }^{12}$-implica, por un lado, cierta ambigüedad por naturaleza en cuanto al término de su existencia; y, por otro, la capacidad de libertad y de adherirse a términos opuestos: «porque el hombre fue creado ser intermedio, ni del todo mortal ni absolutamente inmortal, sino capaz de lo uno y de lo otro». ${ }^{13} \mathrm{O}$, de otra forma, que dado el carácter compuesto del ser humano, en el que el alma se encuentra como recibida en «frágiles y enfermizos cuerpos», el hombre se encuentra «constituido entre el bien y el mal». ${ }^{14}$ Porque en él se contraponen las tendencias de lo corporal y lo anímico.

Así, es esencial al ser humano ser cierto medio, encontrarse in-terminado, con límites aún por fijar: en resumidas cuentas, el hombre ha de hacerse. Es esa indefinición - ser intermedio - la que hace que el hombre tenga que elegir. Lo que pretende justificarse, al fin y al cabo, es que la mortalidad como tal es algo de lo que es culpable el propio hombre. Esto supone que Dios no puede ser el directo responsable del carácter mortal del hombre: «porque si desde el principio le hubiera creado inmortal, le hubiera hecho dios; y, a la vez, si le hubiera creado mortal, hubiera parecido ser Dios la causa de su muerte». ${ }^{15} \mathrm{La}$ bondad de Dios crea un ser capaz de elegir; de este modo, la mortalidad es algo que le llega por libre elección, como consecuencia de sus actos: «el Verbo, antes de crear a los hombres, fue artífice de los ángeles, y una y otra especie de criaturas fue hecha libre [...]. Y el hombre, que había sido creado a imagen de Dios, al apartarse de él el espíritu más poderoso, quedó hecho mortal». ${ }^{16}$ En este sentido, Tertuliano concluye ${ }^{17}$ la no naturalidad del morir, por

10 San Justino Diálogo con Trifón, n. 5, en Padres apologetas griegos, op. cit.

11 Atenágoras, Sobre la resurrección de los muertos, n. 13, en Padres apologetas.

12 Cfr. Tertuliano, Liber de Anima, c. 52.

13 Teófilo de Antioquía, Los tres libros a Autólico, II, n. 24, en Padres apologetas.

14 Lactancio, De div. inst., c. 5.

15 Teófilo de Antioquía, op. cit., n. 27.

16 Taciano, Discurso contra los griegos, n. 7. «Por su desobediencia se atrajo el hombre trabajo, dolor y tristeza, y cayó, finalmente, bajo el poder de la muerte»: Teófilo de Alejandría, op. cit., n. 25. «Fue Cristo al Jordán [...] por amor del género humano, que había caído desde Adán en la muerte y en el error de la serpiente, cometiendo cada uno el mal por su propia culpa»: San Justino, Diálogo con Trifón, n. 88. 
cuanto no puede ser natural lo que acontece por la voluntad del hombre. No hay que olvidar que este carácter medial e interminado toma todo su sentido desde la perspectiva de la finalidad del ser humano. Lactancio, que en el libro VII de De divinis institutionibus intenta comprender dónde se encuentra la beatitud del hombre, precisa claramente cuál es la finalidad del ser humano:«mundus factus est, ut nascamur: ideo nascimur, ut agnoscamus factorem mundi ac nostri Deum: ideo agnoscimus, ut colamus: ideo colamus, ut immortalitatem pro mercede laborum capiamus, quoniam maximis laboribus cultus Dei constat». ${ }^{18}$ Es decir, si en el origen el hombre fue creado como capaz de adherirse o no a su creador, y eligió la muerte; en esta vida se trata de reconquistar la posibilidad de esa inmortalidad perdida. Mas siempre en el marco de la libre elección. Porque, en resumidas cuentas, «mors non extinguit hominem». ${ }^{19}$

De esta forma queda afirmada la mortalidad del ser humano como algo no esencial pero justificada desde la naturaleza humana: su «ser-desigual» —a-nomalian ${ }^{20}$-; es decir, la vida del hombre queda lejos de la impasibilidad de lo absolutamente terminado, sino que está sometida a múltiples sucesos y transformaciones. Atenágoras intentará justificar la muerte admitiendo, a la vez, que la inmortalidad pertenece a las notas propias de la especie humana, en cuanto de naturaleza racional: es decir, ha de pensarse que si «el Creador de todo este Universo hizo al hombre para participar de la vida racional y, hecho contemplador de su magnificencia y sabiduría, que en todo brilla, permanecer siempre en esa contemplación según el designio suyo y según la naturaleza que le cupo en suerte». ${ }^{21}$ De forma que la libre elección del ser humano aparece como elemento fundamental a la hora de aceptar la mortalidad del hombre: el ser humano es mortal por haber elegido contra Dios.

\section{EL MAL}

Igualmente sucede con el mal. Aunque aquí tendremos que hacer algunas matizaciones que, evidentemente, alcanzan también a lo que hemos comentado. Hay mal, en primera instancia, por la libre decisión del hombre. Libre decisión que sigue la de una criatura superior a él: hay que mencionar, obligadamente, a los demonios. Todo tiene su fundamento en la dualidad natural del ser humano que hemos comentado ya. La composición de cuerpo y alma, contrapuestos en su origen y en sus tendencias. Lo terreno y lo celeste. Lo pesado y lo leve. Lo mortal y lo inmortal.«Corpus enim nihil nisi temporale desiderant, id est, cibum, potum, indumentum, quietem, voluptatem [...]. Animus autem per se multa desiderat, quae ad officium fructumve corporis non redundent». ${ }^{22} \mathrm{De}$ donde el hombre se encuentra en

17 Cfr. Liber de Anima, c. 52.

18 Ibid., cap. 6.

19 Lactancio, De div. inst., c. 10.

20 Atenágoras, Sobre la resurrección [...], n. 17.

21 Ibid., n. 13.

22 Lactancio, op. cit., c. 11. 
ese medio que propicia la posibilidad de dos direcciones, la virtud y el vicio. Porque puede decirse que hay algo de natural en el mal — «quodammodo», pues tiene «suum deum et patrem, ipsum scilicet corruptionis auctorem ${ }^{23}$ - aunque lo propiamente natural es el bien. De modo que siempre hay un ingrediente de responsabilidad en el mal. De este modo, el mal queda ya restringido al llamado mal moral. Porque, como es evidente que en Dios «no hay maldad alguna», ${ }^{24}$ todo mal tiene su exclusivo origen en las criaturas haciendo uso de su libertad: «y si el género humano no tiene poder para huir por libre determinación de lo vergonzoso y escoger lo bello, es irresponsable de cualesquiera acciones que haga. Mas, que el hombre es virtuoso y peca por libre elección lo demostramos por el siguiente argumento: vemos que el mismo sujeto pasa de un contrario a otro. Ahora bien, si estuviera determinado ser malo o bueno, no sería capaz de cosas contrarias, ni se cambiaría con tanta frecuencia». ${ }^{25}$

Somos libres, como ya hemos comentado más arriba, y dueños de nuestra indeterminación: por eso, provocamos el mal, somos capaces de adherirnos o separarnos de los valores que han de conducir una correcta existencia.«De este modo, el malo es con justicia castigado, pues por su culpa se hizo malo; y el justo merecidamente es alabado por sus buenas obras, pues pudiéndolo por su libre albedrío, no traspasó la voluntad de Dios». ${ }^{26} \mathrm{Es}$ que si no hubiera libertad no habría responsabilidad, las normas morales carecerían de validez alguna. Todo dentro del tener que ganar la inmortalidad. Que sólo puede ser conseguida a través de la virtud, aniquiladora del vicio - desorden en los apetitos materiales. La virtud dice consecuente referencia a lo imperecedero. El vicio, a todo lo perecedero. Así, la virtud afrenta a la muerte: su premio está tras ella. Y aquí es donde encaja la afirmación de Lactancio de la doble vida y muerte. Hay una doble vida desde la estricta separación alma-cuerpo: la vida del alma y la vida del cuerpo. Del mismo modo, tenemos la muerte en el tiempo - separationem carnis atque animae-inevitable; más una segunda muerte que evitará el virtuoso y padecerá el vicioso. Acontecerá cuando la muerte temporal, separación de cuerpo y alma, acabe. La muerte del alma —puesto que lo corpóreo-terreno vuelve a los elementos de los que surgió - consistirá en penas y castigos infinitos. Además estaba absolutamente convencido de que la otra vida ha de equilibrar lo sucedido en ésta, de forma que la felicidad en esta vida suponga continua miseria en la futura; mientras que una vida terrena de padecimiento y odio de lo temporal habría de ser recompensada por la felicidad eterna.

La libertad, así, es fundamental para justificar el mal en el universo. Mas, también, permite a nuestros autores afirmar la inmortalidad. ¿Sería justo que el que no ha hecho más que mal en esta vida - y evidentemente no paga por él- no recibiera su castigo? $\mathrm{O}$ en el caso contrario, habría que premiar la conducta de aquéllos que han hecho bien y no han sido

23 Tertuliano, Liber de Anima, c. 41.

24 San Justino, Apología I, n. 6. «Si le llamo providencia, nombro su bondad»: Teófilo de Antioquía, Los tres libros a Autólico, I, n. 4.

25 San Justino, op. cit., n. 43.

26 Taciano, Discurso contra los griegos, $n .7$. 
reconocidos por ella. Y esto sólo es posible no sólo afirmando la inmortalidad del hombre sino la necesidad de la resurrección: «si el Hacedor de los hombres tiene algún cuidado de sus propias hechuras y en alguna parte se guarda la justa distinción entre los que vivieron bien y los que vivieron mal, ello será o en la presente vida [...] o después de la muerte [...] ni después de la muerte»; ${ }^{27}$ y no después de la muerte porque entonces el cuerpo se descompone: y siendo el hombre unidad de cuerpo y alma, no puede pedirse que la parte —el alma - pague por el todo. Así, si ha de haber justicia «menester es de todo punto que se dé la resurrección de los cuerpos muertos y hasta totalmente disueltos y que nuevamente se reconstituyan los mismos hombres». ${ }^{28} 0$ sea, que queda justificada la resurrección por la inevitable justicia universal.

Pero la ejecución de esa libertad que persigue algo contrario a lo divino es pensada, como hemos dicho, no como algo que puramente se inicia en el hombre, sino como la continuación de la negación iniciada por un ser superior a él. Y es que el hombre no es la única criatura racional creada: hay otras con determinadas funciones en el universo. «Decimos existir una muchedumbre de ángeles y ministros, a quienes Dios, Hacedor y Artífice del mundo, por medio del Verbo que de él viene, distribuyó y ordenó para que estuvieran en torno a los elementos y a los cielos y al mundo y lo que en el mundo hay, y cuidaran de su buen orden». ${ }^{29}$ Así, estos «ángeles y ministros» han de cuidar del mundo, de forma que el des-cuido se materializará en el des-orden: en la posibilidad del mal. «Ellos -es decir, aquellos ángeles que se separan de Dios- son los que sembraron entre los hombres asesinatos, guerras, adulterios, vicios y maldades de toda especie». ${ }^{30} \mathrm{La}$ elección del mal en el hombre continúa la del que se rebela contra Dios: «sucedió, sin embargo, que a uno que, por ser criatura primogénita, aventajaba a los demás en inteligencia, le siguieron los hombres y los ángeles y le proclamaron Dios, a aquél justamente que se había rebelado contra la ley de Dios [...] y el que fuera primogénita por su transgresión e insensatez fue declarado demonio, y los que imitaron sus fantasías resultaron el ejército de los demonios». ${ }^{31}$ Atenágoras es más explícito en el momento de explicarnos cómo es posible que se aparten de Dios: «entendemos que existen otras potencias que rondan la materia y la penetran y una contraria a Dios; no porque haya nada contrario a Dios al modo como la discordia a la amistad, según Empédocles [...]; sino porque el espíritu que ronda la materia es contrario a su bondad [...]. Pero a la manera que los hombres tienen libre albedrío y pueden optar por la virtud y por la maldad [...] así también en los ángeles. Unos permanecieron en lo que Dios los creó y ordenó, otros se enorgullecieron tanto de su naturaleza como por el imperio que ejercían, a saber, éste que es príncipe de la materia y de las formas de ella y los otros encargados de este primer firmamento [...]; éstos, por haber caído en deseo

27 Atenágoras, Sobre la resurrección[...], n. 19-20.

28 Ibid., n. 25.

29 Atenágoras, Legación en favor de los cristianos, n. 10.

30 San Justino, Apología II, n. 4.

31 Taciano, Discurso contra los griegos, n. 7. 
de vírgenes y mostrándose inferiores a la carne; aquél, por haber sido negligente y malo en la administración que se le confiara». ${ }^{32}$ El orgullo del poder se transforma en maldad: la desmesura implica la imposibilidad de mantener el orden establecido por Dios - la desmesura es creer ser Dios-, la imposibilidad de ser lo que se debe ser. Así, el no-deberser ontológico lleva al no-deber-ser moral.

La desobediencia es desorden y mal. Por el príncipe del mal, el hombre es llevado al desorden: ha sido dañado en su inteligencia - «cuando un demon quiere hacer mal a un hombre, le daña primero la inteligencia ${ }^{33}$ - , su capacidad de juzgar rectamente, su sentido de la corrección y la justicia. Sin duda, «la acción de éstos [demonios] es la destrucción del hombre». ${ }^{34}$

Mas, igual que fue libre para separarse de Dios, lo es ahora para intentar rectificar tal acción. Y ésta es la vida: la separación que conduce al orden o lo contrario. Separándonos del mal, en el hombre el alma se unirá al espíritu y seremos imagen y semejanza de Dios. En el caso contrario, «el hombre no se aventaja a las bestias más que por su voz articulada». ${ }^{35}$ De cualquier forma, haga lo que haga, la recompensa o el castigo es algo que alcanzará al hombre como unión de cuerpo y alma: en su integridad. El hombre es considerado, en estos primeros autores, como una totalidad capaz de bien y de mal; influido por el mal, mas con conocimiento de lo que verdaderamente ha de hacer, a través del que ha venido a liberar al hombre de la muerte.

Podemos concluir que el tratamiento dado al mal y la muerte pasa por dos parámetros fundamentales, la libertad de la criatura racional y su naturaleza interminada. Esto es lo que permite y posibilita la separación, el desorden, la desmesura, el no deber ser; así como el camino contrario.

32 Atenágoras, Legación en favor[...], n. 24.

33 Ibid., n. 26.

34 Tertuliano, Apologeticus, c. 22, en P.L., I.

35 Taciano, Discurso contra los griegos, $\mathrm{n} .15$. 